\title{
Advances in microsurgery for upper and lower extremity reconstruction and limb preservation
}

\author{
Alberto Bolletta ${ }^{1,2}$, Rubino Corrado ${ }^{2}$, Hung-Chi Chen ${ }^{1}$ \\ 'Department of Plastic Surgery, China Medical University Hospital, Taichung 404, Taiwan. \\ ${ }^{2}$ Department of Medical, Surgical and Experimental Sciences, UHT of Sassari, Plastic Surgery Unit, University of Sassari, Sassari \\ 07100, Italy.
}

Correspondence to: Dr. Hung-Chi Chen, Department of Plastic Surgery, China Medical University Hospital, 2 Yude Road, Taichung 404, Taiwan. E-mail: d19722@mail.cmuh.org.tw

\begin{abstract}
How to cite this article: Bolletta A, Corrado R, Chen HC. Advances in microsurgery for upper and lower extremity reconstruction and limb preservation. Plast Aesthet Res 2019;6:22. http://dx.doi.org/10.20517/2347-9264.2019.22
\end{abstract}

Received: 1 Sep 2019 First Decision: 1 Oct 2019 Revised: 15 Oct 2019 Accepted: 17 Oct 2019 Published: 24 Oct 2019

Science Editor: Matthew L. lorio Copy Editor: Cai-Hong Wang Production Editor: Jing Yu

\begin{abstract}
In the recent decades, microsurgical reconstruction has evolved from simple survival of the affected extremity to the improvement of functional and aesthetic outcome. This review retraces the main contributions to the advances of microsurgery for reconstruction of upper and lower extremities and limb preservation. In the upper extremity, it is important to restore fine motility, together with allowing prompt mobilization. In the lower limb, care must be taken in the reconstruction of weight-bearing areas and the aim must be proper ambulation and shoe wearing. Local perforator flaps can be considered for medium size defects. They provide thin coverage and can be performed in short operating time. Their use, though, is often limited by tissue availability. Free flaps allow to overcome this problem and, thanks to the recent development in the study of perforator vessels, the microsurgeon can choose the flap with the most appropriate characteristics. Chimeric flaps can accomplish simultaneous reconstruction of different tissue components and large bone defects often require vascularized bone reconstruction. When dealing with limb preservation it is very important to consider residual functionality. Functioning muscle transfer and targeted muscle re-innervation can be performed in these cases. A useful reconstructive tool in severely damaged limbs with limited blood supply is the use of cross-leg free flaps. In conclusion, extremity reconstruction and limb preservation are reaching new heights thanks, not only to the work of plastic surgeons, but also to the new developments in other fields of study such as oncology, traumatology, radiology and medical engineering.
\end{abstract}

Keywords: Extremity reconstruction, functional and aesthetic outcome, limb salvage, perforator flaps, free flaps, weight-bearing areas, cross-leg flaps

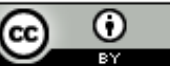

(C) The Author(s) 2019. Open Access This article is licensed under a Creative Commons Attribution 4.0 International License (https://creativecommons.org/licenses/by/4.0/), which permits unrestricted use, sharing, adaptation, distribution and reproduction in any medium or format, for any purpose, even commercially, as long as you give appropriate credit to the original author(s) and the source, provide a link to the Creative Commons license, and indicate if changes were made.

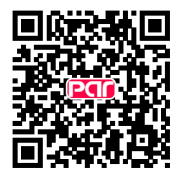




\section{INTRODUCTION}

Nowadays, the development of both trauma care and oncological treatments increased the number of situations in which plastic surgeons are called to perform difficult limb salvage and complex, tridimensional reconstructions. Fortunately, sophistication of microsurgical techniques and improvements in the comprehension of the blood supply to tissues in different areas of the body allow the ongoing evolution of reconstructive tissue transfer ${ }^{[1]}$. This enables surgeons, not only to extend the indication for limb preservation but also to obtain better results, in terms of both aesthetic and function recovery. Due to their highly specific characteristics, the techniques and goals of reconstruction are different in the upper and lower extremity. The upper limb represents the area responsible for fine movements essential in everyday life, but it is also often exposed and involved in social relations. Therefore, both functional and aesthetical reconstruction should be achieved. In the lower extremity, reaching a functional reconstruction that allows the patient to walk properly without pain is the primary goal, even though, nowadays, reaching an aesthetic reconstruction is always desirable, when possible $e^{[2-4]}$. Today, many have come to agree that a microsurgical approach is the standard of care in most cases of extremity reconstruction and limb preservation ${ }^{[5]}$. Many different flaps can be used in order to reconstruct bone defects, muscular function and soft tissue coverage. Advances in microsurgery allows to overstep Levin's reconstructive ladder with specific and patient-customized reconstructive approaches ${ }^{[6-9]}$.

\section{Upper extremity}

Defects of the upper extremity may involve different tissue types with specific functions (i.e., muscles or tendons involved in hand and finger mobility) and large coverage area that allows secondary procedures, if needed $^{[10]}$. It would be preferable to avoid flaps that need to sacrifice the radial or ulnar artery, in order not to alter and diminish the vascular inflow and outflow from the already damaged limb, causing not only sensory alteration and cold intolerance but also chronic edema and tissue ischemia ${ }^{[11-13]}$. If the function of flexors or extensors of fingers or other joints (i.e., wrist or elbow) is damaged, a functioning muscle transfer may be used ${ }^{[1,15]}$. Goal of upper limb reconstruction is to restore fine functions of the hand, together with aesthetic coverage that allows prompt mobilization of the hand and joints in order to avoid stiffness from prolonged immobilization.

\section{Lower extremity}

When planning a microsurgical reconstruction, it has to be taken into account that the lower limb presents greater risks compared to other districts ${ }^{[16]}$. These are represented by the status of the vascular network in the lower extremity, which may be affected by many conditions such as peripheral vascular disease or diabetes, and also by the fact that the area is responsible for weight bearing. The skin coverage in most of the lower leg is thin and tight over muscles and sometimes directly over the bone ${ }^{[17,18]}$. Sometimes circumferential coverage is needed and post-operative edema and scarring have to be taken into consideration ${ }^{[18]}$. Therefore, lower limb reconstruction is one of the most challenging, with a higher incidence of free flap loss compared to microsurgical reconstructions performed in other districts ${ }^{[19-23]}$. Patients in need of lower extremity reconstruction also include various number of traumatic injuries. For this reason, it is extremely important, in evaluating the patient and developing the reconstructive strategy, to assess the condition of vessels in the extremity ${ }^{[20]}$. When Gustilo classification system was firstly introduced, it already highlighted the fact that limb perfusion was essential in determining reconstructive options. In fact, type IIIC describes devascularized limbs needing vascular repair as having the worst prognosis ${ }^{[24,25]}$. Goal of lower limb reconstruction is to restore the fundamental functions, the possibility to walk and wear shoes, together with proper coverage in order to avoid recurrent ulceration and acceptable aesthetic result. 


\section{SOFT TISSUE COVERAGE}

\section{Local perforator flaps}

Over the past two decades the indications for perforator flaps reconstruction have increased due to the better understanding of the anatomy and distribution of perforator vessels ${ }^{[5,26]}$. These flaps can be used as local flaps and transposed to the defect through a wide range of movements (i.e., V-Y advancement, rotation, etc. ${ }^{[27-30]}$. A propeller perforator flap is, according to Tokyo consensus, "a perforator flap with a skin island made of two paddles, one larger and one smaller, separated by the nourishing perforating vessel that corresponds to the pivot point ${ }^{\text {p[31] }}$. Propeller perforator flaps have a low donor-site morbidity due to conservation of source vessels and muscles and provide like-with-like tissue coverage in terms of color match, thickness and texture. These flaps can be raised in a short time and can be designed almost in every location. Local flaps can be contraindicated in trauma patients, when the extent and the characteristics of the injury affect the viability of the surrounding tissues, for example in degloving injuries. Another questionable fact is that the vessel chosen for these flaps is usually close to the injured area but, if the perforator is not directly damaged, it usually does not undermine the flap survival ${ }^{[32]}$. In patients with compromised general conditions, the time and cost saving procedures, sparing multiple surgical sites, can be a first choice ${ }^{[33-37]}$. It is also true, though, that propeller perforator flaps have been related to higher rates of complications, such as partial flap necrosis and venous congestion. Such complications appear to be related to two main topics, still objects of debate, regarding propeller flaps: dimensional limit and arc of rotation. The limit in terms of size of these flaps is hard to determine due to the dynamicity of adjacent perforasomes recruitment which depends on many different factors ${ }^{[38]}$. The arc of rotation, instead, has been determined to be related to the length of the pedicle and its proper and wide dissection ${ }^{[39-41]}$.

In limb reconstruction, local propeller perforator flaps can be considered as an important tool for the reconstruction of small and medium size defects. Due to the lack of tissues in the limbs, attention has to be payed to donor site morbidity. In the upper limb, direct donor site closure can be achieved for flaps with $4 \mathrm{~cm}$ of width or less in the forearm, and $2 \mathrm{~cm}$ in the dorsum of the hand. Partial donor site closure can be performed in greater defects, and total closure attained with skin grafting ${ }^{[32]}$.

Useful propeller perforator flaps of the upper limb are the one based on radial artery perforators and ulnar artery perforators. They are both pliable, thin, have a very good texture match, and can be used as sensate flaps, which is very important in upper limb reconstructions. If multiple tissue types are needed their harvest can incorporate bone and portions of tendons and muscles. If these flaps are based on proximal perforators they can be used for proximal defects, such as the elbow region, whereas, if they are based on distal perforators they can provide tissue coverage for the wrist area and the hand. In terms of donor site morbidity, the ulnar artery propeller perforator flaps have the advantage of a minor tendon exposure, especially if raised in the proximal forearm ${ }^{[42]}$. Posterior and anterior interosseous artery propeller perforator flap can be used for the dorsum of the hand because of their characteristics very similar to the hand structure ${ }^{[43]}$. For small defects of the hand and fingers, both volar and dorsal, another good option is the dorsal metacarpal artery perforator flap.

In the lower extremity, according to 2016 Bekara's meta-analysis, the most used propeller perforator flaps are posterior tibial artery perforator $(58.6 \%)$, peroneal artery perforator $(30.1 \%)$, sural artery perforator (medial or lateral, 5.6\%), metatarsal artery perforator $(2.0 \%)$ and anterior tibial artery perforator $(1.6 \%)^{[44]}$. Flap selection is usually based on the location of the defect and on the study of the perforators in the nearby area. Preoperative color Doppler ultrasound can be used to detect adjacent perforator vessels with suitable caliber and blood flow. Usually vessel selection includes vessels in a $2-10 \mathrm{~cm}$ range from the defect, with caliber greater than $0.6 \mathrm{~mm}$. After the choice of the perforator, the design of the propeller flap is performed ${ }^{[45]}$. In terms of complication rates of propeller perforator flaps in the lower limb, two recent review articles by Gir and Nelson reported analogous results (11\% of partial flap necrosis in both studies, 
and $1 \%$ and $5 \%$ of total necrosis ${ }^{[46,47]}$. Bekara et al ${ }^{[44]}$ in 2016 presented a comparison between free flaps and pedicled propeller flaps in the distal third of the lower extremity by performing a systematic review with meta-analysis of all published data. In order to analyze the data, they included under "coverage failure" both partial and total flap necrosis needing a second reconstructive procedure. They did not find a statistical significance in the difference of coverage failure between the two groups, even though it was rather more frequent in the free flaps group. On the other hand, partial necrosis affected more the propeller flaps group, but not undermining their overall success rates. By showing that complication rates were comparable in the two groups, they suggested that the flap of choice may be decided depending on defect size, using pedicled-propeller flaps for smaller defects and free flaps for larger ones.

\section{Free flaps}

Despite all the stated above on pedicled perforator flaps, it is true that free flaps present many advantages which makes them an irreplaceable tool in extremity reconstruction. Pedicled flaps are inevitably limited by restricted tissue accessibility and characteristics ${ }^{[48]}$. On the other hand, free flaps can be chosen and custom designed according to the defect ${ }^{[1]}$. Characteristics of an ideal free flap are similarity with defect area and tissue reliability to allow secondary surgeries. Donor-site morbidity should be minimal. A long pedicle is always an advantage because it allows safer microanastomosis, further away from the wounded area ${ }^{[49,50]}$. In upper extremity reconstruction, it is advisable to perform end-to-side anastomosis in order to spare main vascular axis and avoid reducing hand perfusion ${ }^{[5]]}$. Muscular, fasciocutaneous and cutaneous flaps can all be used in extremity reconstruction.

\section{Muscle flaps}

For many years muscle flaps have been the first choice for the lower limb reconstruction and are still a reliable option in many cases. Muscular flaps were preferred because of their usually long pedicle, relatively easy harvest, capability of obliterating dead space in large defects and better conforming to the irregular surface of the wound or plates used for bone fixation ${ }^{[52]}$. Due to their capacity of improving blood supply, their use have also been indicated when dealing with wounds with high infection risk ${ }^{[53,54]}$. Even in the upper extremity they have been used for large defects, in particular in the proximal arm, where they are still bulky at the beginning, but, thanks to progressive atrophy and revisions it is possible to obtain acceptable results ${ }^{[10,55]}$. However, muscle flaps have downsides such as sacrificing a functioning muscle and requiring coverage, often with skin grafts. This affects the aesthetic appearance of the reconstruction. Moreover, muscle flaps may limit tendon gliding and their elevation for secondary surgeries (i.e., tenolysis) is harder ${ }^{[5]]}$. Most commonly used muscle flaps are, according to many authors, latissimus dorsi, serratus anterior, rectus abdominis and gracilis ${ }^{[56-58]}$. The latissimus dorsi presents many advantages and it is a considered a "workhorse" flap. It is the largest muscle available and is a very good option for covering large areas, including exposed tendons, nerves and bone. Its dissection is quite easy and its pedicle has reasonable length and caliber, making it a reliable flap ${ }^{[52,59]}$. It may be necessary, depending on the defect, to change the position of the patient for flap harvesting and this can be time and effort consuming. The same disadvantage has to be considered for serratus anterior muscle flap, together with the difficulties in sparing the long thoracic nerve during pedicle dissection, in order to avoid winged scapula ${ }^{[60-63]}$. The serratus anterior flap can be raised as a small muscle flap with a long pedicle, and it is usually indicated in smaller defects without close recipient vessels. Portion of a rib can be raised with the flap if a bone component is needed for reconstruction. The rectus abdominis muscle flap is a bulky flap suitable for obliterating space in deep, moderate-size wounds. Donor site morbidity is its major concern, with abdominal bulge and hernia formation ${ }^{[11,64-66]}$. Free muscle flaps are also used for functioning muscle transfer in upper and lower extremity. The latissimus dorsi flap can be used by harvesting the thoracodorsal nerve, which is responsible for its motor function, but, in many cases gracilis flap is preferred. The gracilis muscle has similar characteristics to the muscles of the forearm and a tendinous portion suitable for digits tendon attachment. For these reasons, gracilis flap is a very useful flap in finger function restoration with very little donor site morbidity ${ }^{[1]}$. 


\section{Cutaneous and fasciocutaneous flaps}

Compared to muscle flaps, fasciocutaneous flaps allow supple and thin coverage with ideal surfacing, without needing skin grafting. They are also better re-elevated in case of secondary surgeries ${ }^{[17,56,57]}$. Due to the many different perforator flaps described, it is often possible to choose a flap with suitable characteristics without needing to change the patient's position, and often allowing a two-team approach in order to reduce operative time. If the deep fascial layer is not needed for reconstructive purposes, cutaneous flaps can be elevated above it, including suprafascial components nourished by the perforator vessel. Preserving the deep fascia reduces donor site morbidity and chances of muscle herniation. It also allows harvesting thinner and more pliable flaps, which can be designed in order to better match the characteristics of the defect. Sensory nerves can be included for reinnervation and superficial veins to increase the venous outflow ${ }^{[67]}$. The flap can be thinned during or immediately after harvesting, hence maximizing aesthetic results with a reduced need for surgical revisions ${ }^{[68]}$. Obviously, the perforator dissection of these flaps is technically demanding and it may result in small caliber vessels anastomosis, requiring high surgical skills and knowledge of vascular anatomy ${ }^{[69,70]}$. The characteristics of these flaps have increased their use as first option in difficult upper limb reconstructions, where it is extremely important to achieve optimal coverage and early rehabilitation.

Wang et al ${ }^{[51]}$ in 2017 reviewed the evidence for application of different important perforator flaps in upper extremity reconstruction, such as the anterolateral thigh (ALT), superficial circumflex iliac perforator (SCIP), deep inferior epigastric perforator (DIEP) and superficial inferior epigastric artery (SIEA) flaps. The ALT resulted in being the most versatile flap, due to the possibility of harvesting it thicker or thinner, therefore functional both in larger defects of the proximal arm and distally, where a thin and supple flap is needed. The SCIP flap finds its indication in the hand and wrist area [Figure 1] whereas the DIEP and SIEA flaps are better suited for the proximal arm. Many authors have reported the use of free fasciocutaneous flaps in the lower extremity, even in complicated cases with open fractures, chronic osteomyelitis, diabetic complications and limb salvage ${ }^{[56,57,71-75]}$. The ALT is the flap of choice in many cases, especially in open traumatic wounds, with fractures of the tibia, ankle and foot ${ }^{[5,58,72]}$. It can be utilized with a portion of the fascia lata to reconstruct tendons as well (i.e., the Achilles) ${ }^{[76]}$. Abdelfattah et al. ${ }^{[5]}$ evaluated free perforator flaps, other than ALT, for the reconstruction of lower limb defects, including superficial circumflex iliac perforator (SCIP), gluteal artery perforator (GAP), thoracodorsal artery perforator (TDAP), deep inferior epigastric perforator (DIEP), posterior interosseous artery perforator (PIAP), upper medial thigh perforator, and medial sural artery perforator (MSAP) flaps in their 563 cases experience. They propose an algorithm for flap selection based on the characteristics of each flap ${ }^{[5]}$. Other than the already described ALT, SCIP and DIEP flaps, GAP flaps appeared to be indicated in moderate size defects located in the posterior body surface but, as a drawback, they have a short pedicle and may require supermicrosurgical technique ${ }^{[77,78]}$. TDAP flap on the other hand have a long pedicle and can be utilized as a composite flap by harvesting it with scapular bone ${ }^{[79,80]}$. PIAP and MSAP flaps provide excellent single-stage coverage for small defects in the lower leg and foot ${ }^{[8]]}$. This study suggests the reliability of free perforator flap reconstruction for lower extremity defects. Their series of 552 patients had a high success rate (96.2\%), even though they treated a large number of diabetic limb salvage cases. Previous works reported achieving similar rates of success in using perforator flaps in complicated lower extremity reconstructions ${ }^{[17,56,57,74,75]}$.

\section{WEIGHT-BEARING ISSUE IN THE LOWER LIMB}

In lower limb reconstruction weight-bearing areas may be involved, where the epidermal-dermal layer is thicker and attached, through fibrous connective tissue, to the plantar aponeurosis. Fat lobules are located within these fibrous septa. This structure provides shock-absorbing function and prevents shear ${ }^{[82]}$. In order to reconstruct this area like-with-like, the medial plantar flap was introduced. It was initially described as a cross-leg flap but it has been used since, both as pedicled, for ipsilateral defects, and as a 

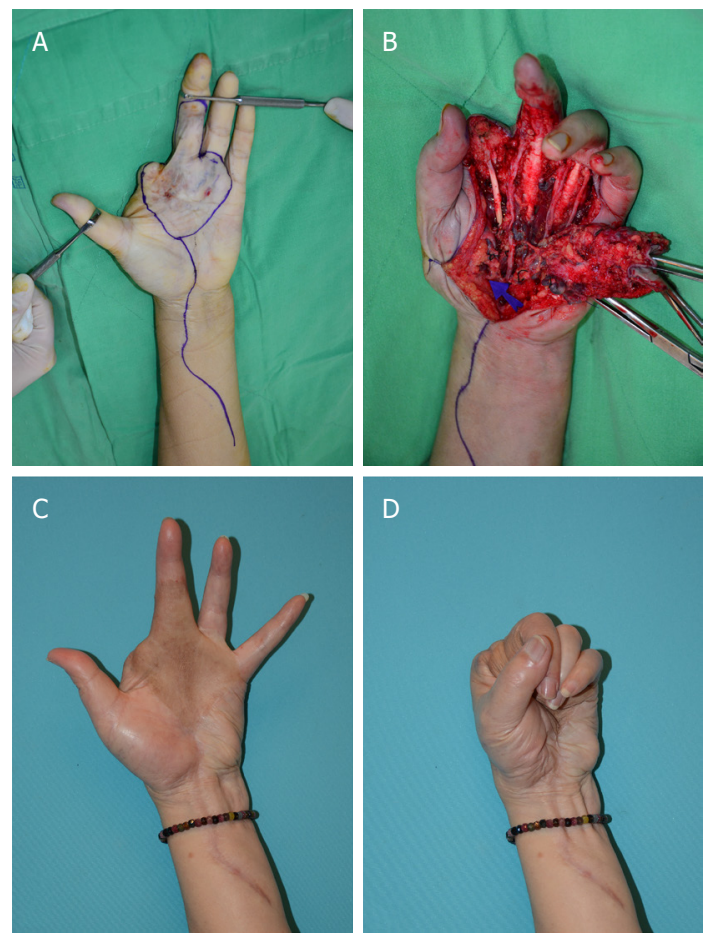

Figure 1. A: The 45-year-old woman was affected by arteriovenous malformation of the left hand. The index finger had been previously amputated due to recurrent and excessive bleeding. Before surgery, the residual lesion was marked according to angiography study; B: the arteriovenous malformation was excised, after delicate dissection, under the aid of tourniquet; C: the defect was covered with a thin SCIP flap. It provided good coverage of the tendons and nerves. Postoperatively, the range of movement was satisfactory. This picture shows complete extension of fingers; D: good dexterity of fingers was achieved with thin flap coverage. As shown, the patient can completely flex the fingers and good sensation of the finger tips was preserved

free flap ${ }^{[83-85]}$. It can be used as a sensate flap, offering ideal tissue for medium-sized defects with low donor site morbidity, therefore an excellent option for coverage of the heel or the forefoot ${ }^{[8]}$. In reconstruction of larger weight bearing areas free flaps are needed and the choice between muscle or fasciocutanous flaps can be difficult. Fasciocutaneous flaps have the advantage of providing supple tissue that allows aesthetical and, if innervated, sensate reconstruction. On the other hand, they present high shear modulus in the subcutaneous tissue, therefore determining instability ${ }^{[87,88]}$. The same problem affects muscle flaps, but it seems to reduce with progressive muscle fibrosis due to atrophy. Over time, also the appearance of skin grafted muscle flaps improves. They may still, though, incur in ulceration due to lack of sensation ${ }^{[89]}$. Fox et al ${ }^{[90]}$ in 2015 performed a systematic review in order to evaluate the outcomes of heel reconstruction with fasciocutaneous or muscle free flaps. They analyzed outcomes in terms of complication rate, revision surgeries, time to mobilization and requirement for specialized footwear. Their work reported no significant differences between the two groups, even though they admit that "the current evidence is largely limited to small cohort studies (level IV evidence) ${ }^{\text {,[90] }}$.

\section{BONE RECONSTRUCTION}

In the upper extremity, bone defects greater than $6 \mathrm{~cm}$, both resulting from oncological resections or traumatic injuries usually require a vascularized bone transfer, especially if there is risk of infection. The free fibula flap is ideal for reconstruction of the long bones of the arm, due to its characteristics and shape ${ }^{[91-93]}$. Its harvest presents low donor site morbidity, mostly represented by flexion contracture of the great toe and ankle pain ${ }^{[94-96]}$. The medial femoral condyle is a valuable option in smaller upper extremity bone defects, in particular in the carpal region. This vascularized cancellous bone can be used to treat nonunion and avascular necrosis of the scaphoid ${ }^{[97,98]}$. Donor site morbidity is represented by knee pain and seroma formation ${ }^{[99]}$. 

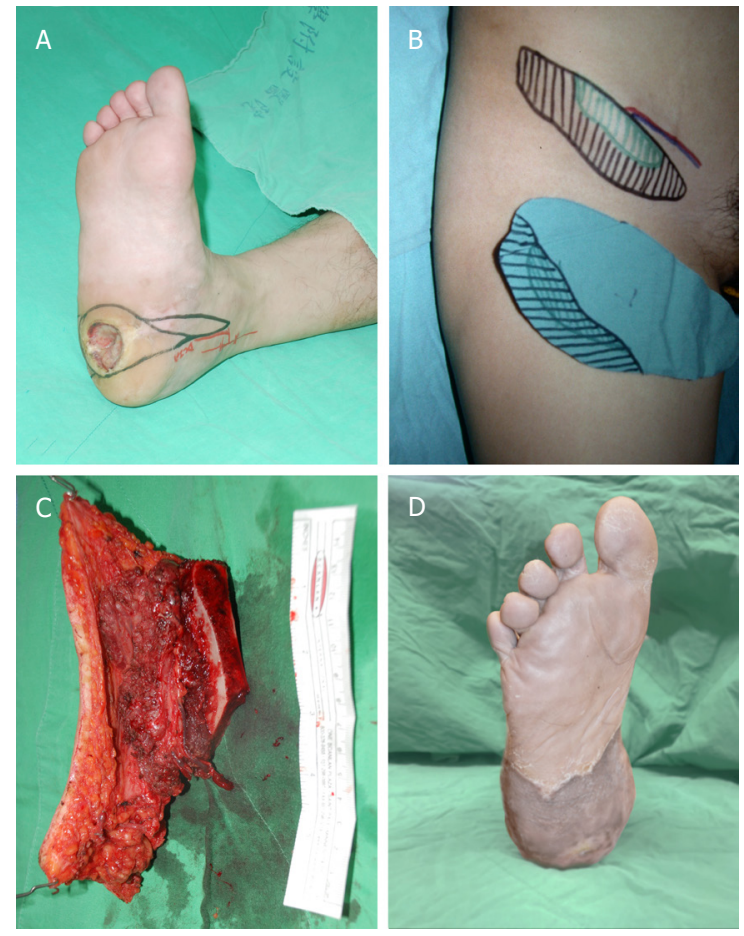

Figure 2. A: 32-year-old woman with necrosis of the skin of the right heel and part of the calcaneus secondary to crush injury due to motorcycle accident; B: an iliac osteocutaneous flap designed from the right groin area; C: the flap provided simultaneous skin coverage and bone reconstruction for the defect of calcaneus. The soft tissue of the flap was trimmed to fit the contour of the heel; D: the postoperative contour was good and the patient could wear regular shoes

In the lower limb, the loss of a significant portion of the tibia, both traumatic or due to oncological resections, can be difficult to treat. Even though critical-sized tibial bone defects are common, their treatment still represents a challenge. A strategy frequently used in orthopedic surgery is bone transport, which consists of the gradual and progressive translocation of a section of bone to the defect from an healthy area in proximity ${ }^{[100]}$. Traumatic injuries though, often present with open factures and soft tissue defects, increasing the risk of infections. A microvascular bone flap transfer is usually indicated in bone gaps greater than $6 \mathrm{~cm}$. Again the "workhorse" is considered the free fibula flap ${ }^{[101]}$. For coverage and monitoring purposes, a skin paddle is often harvested with the flap. Even though bone stabilization is needed, it is important to minimize it in order to avoid compromising the blood supply to the transferred bone ${ }^{[102]}$. Weight-bearing need to be progressive and complete healing may take up to 6 months ${ }^{[103]}$. If the bone defect affects the calcaneus, for example after total calcanectomy, the reconstruction needs to focus both on the weight-bearing forces involved and on functional outcome. Bone reconstruction depends on defect size and can range from bone allografts to free vascularized bone transfer such as fibula flap or iliac crest flap ${ }^{[104]}$ [Figure 2]. Reconstruction of Achilles tendon have to be performed in order to restore function ${ }^{[105]}$.

\section{DEVASCULARIZED LIMBS}

When dealing with severe mutilating upper and lower extremity injuries with devascularized limbs, the progress made by reconstructive microsurgery, together with progresses in trauma management, microvascular techniques, and skeletal fixation have helped developing stronger reconstructive alternatives to amputation. Even when amputation is necessary, the new approach with targeted muscle reinnervation have shown encouraging results in treating neuroma and phantom limb pain. Moreover, technologic developments in robotics and signal processing, as well as advancements in neuroplasticity research keep 
expanding targeted muscle reinnervation applications in prosthesis control ${ }^{[106]}$. Older studies reported complex Gustilo type IIIC injuries result in very high amputation rates, together with high and unjustified costs for the healthcare system and the patients ${ }^{[107-109]}$. Recent studies, though, evaluated the impact of salvaged limbs both on patients' quality of life and costs for the healthcare system, suggesting it to be beneficial in both instances ${ }^{[110,111]}$. Moreover, in these complicated cases, the introduction of devices such as the topical negative pressure therapy, has allowed surgeons to improve the local general conditions in terms of reduction of bacterial load and creation of a wound bed more suitable for a reconstructive attempt. Despite this, the management of these complex injuries is still debated. It has been demonstrated by several studies that vascular injury increases the severity of trauma ${ }^{[23]}$. Stranix et al ${ }^{[20]}$, compared Gustilo IIIB injuries with increasing arterial injury, finding that limbs with a single vessel uninjured had higher flap failure risk ${ }^{[20]}$. A recent work by Ricci et al. ${ }^{[112]}$ though, compared the reconstructive outcomes of patients with Gustilo type IIIC injuries after emergent revascularization in order to determine whether there was an optimal treatment algorithm. According to their results, the rates of complications in these patients were comparable with the routinely reconstructed type IIIB injuries, therefore worth considering for limb salvage.

Both in upper and lower extremity, if the vascular defect is located within the soft-tissue defect, a flowthrough flap can be considered as a reconstructive option. It may allow reconstruction of both vascular continuity and coverage with a single procedure ${ }^{[113]}$. Different studies have shown that free flow-through flaps can be useful for emergency treatment of complex limb injuries with high success rate ${ }^{[113,114]}$. Even though bringing a vascularized tissue to the injured leg or arm can already be beneficial for the overall blood supply of the region, a flap with flow-through anastomosis will certainly increase the perfusion of the distal limb. This also present other advantages such as increasing direct venous return and reducing edema formation, therefore improving the salvage rates ${ }^{[114]}$. Fujiki et al ${ }^{[115]}$ analyzed whether flow-through anastomosis affects the failure rate of free flaps, compared with traditional end-to-end and end-to-side anastomosis techniques. According to their clinical findings, in the leg, flow-through anastomosis for both the artery and vein had an excellent success rate. Moreover, flow-through venous anastomosis tended to reduce failure rates compared with conventional techniques.

Sometimes in devascularized limb salvage, local tissue is not available and direct free flap reconstruction can't be performed due to the lack of adequate recipient vessels ${ }^{[116]}$. Since World War II, a valuable option in these cases have been represented by cross-leg flaps, giving the possibility of transferring contralateral healthy tissue to the injured lower limb ${ }^{[117,118]}$. The use of this technique has continued over time, with different cross-leg flaps reported, and satisfying outcomes ${ }^{[119-121]}$. Advances in microsurgical techniques have enhanced direct reconstruction but, some of the new concepts, such as free flaps and flow-through flaps, can be applied also to cross-leg flaps. Cross-leg free flaps can therefore be performed as a free flap firstly anastomosed to contralateral recipient vessels and then, secondarily, autonomized on the affected limb random blood supply. These reconstructive approach, in our experience, can be utilized in the distal third of leg, in case of large size defects with the absence of usable recipient vessel ${ }^{[122]}$. When the extent of the injury requires further reach and a longer flap, a flow-through free flap can be used as a carrier for a second free flap. The free cross-leg bridge flap is anastomosed to contralateral recipient vessels granting a sufficient blood supply to the second free flap in order to reach and provide coverage for the entire defect. In our experience, the radial forearm free flap is best suited a vascular bridge flap. The skin paddle can be incised in a "bone" shape, with wider extremities to cover the anastomosis sites. The choice of the second free flap depends on defect size and characteristics. LD or vertical rectus abdominis myocutaneous flaps can be used for wide defects, moreover LD flap can be raised with portion of 1 or 2 ribs, for bony reconstruction. Initially the free flaps were raised in two stages, allowing assessment of the radial forearm flap survival before second flap harvest. In our latest experience, we feel confident that the procedure can be performed in a single stage. In the second surgery, an external fixator is used in order to avoid damages to the flap 

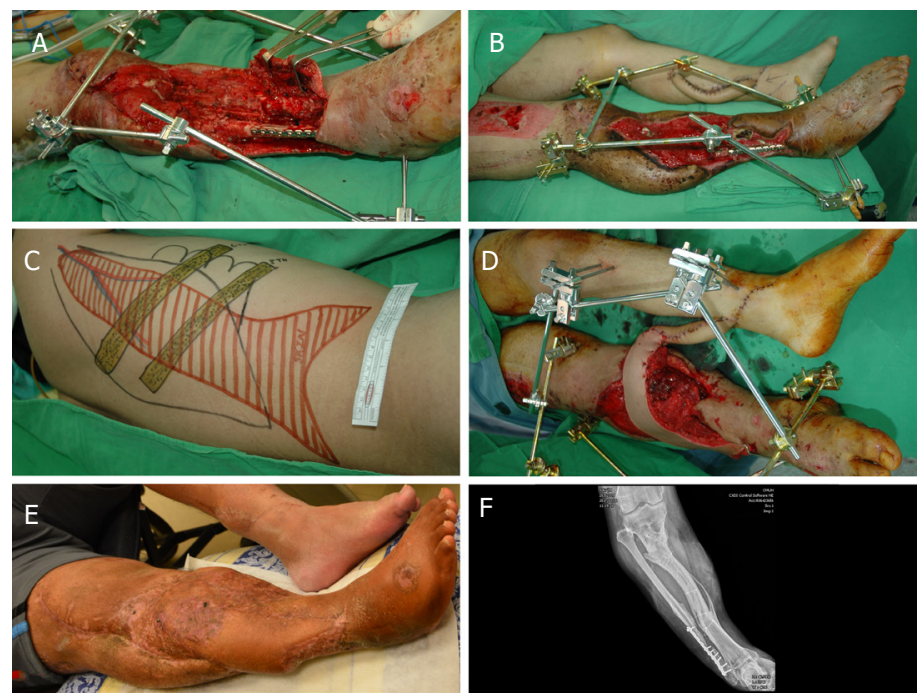

Figure 3. A: The 25-year-old patient had a severe crush injury to his right lower limb in a car accident. The leg survived after thrombectomy of the right femoral artery. There was a $12 \mathrm{~cm}$ defect of the right tibia after debridement, and the fractured fibula was plated as shown; B: there was no available recipient artery in the thigh and leg. In the first stage operation, a radial forearm flap was used as a vascular bridge flap, it was connected to the posterior tibial artery of the left leg in end-to-side fashion; C: in the second stage operation, a free flap was harvested from the back, including myocutanous latissimus dorsi and the lower part of serratus muscle, carrying two ribs (6th and 8th); D: the flaps were connected to the free end of radial forearm flap. The two legs were temporarily bound together with an external skeletal fixator; E: four weeks later, the bridge was divided and part of the radial forearm flap was used for coverage of the residual defect of the right leg; F: bone union was achieved and, with proper physiotherapy, the right leg was gradually trained to resume weight-bearing. As shown, the ribs increased thickness, in a long term follow up

pedicle. In the meantime, the patients undergo physical therapy to preserve muscle status and function during immobility. After 3-4 weeks, the flaps undergo ischemic preconditioning by clamping the pedicle every day for 15 minutes. Indocyanine green angiography can be used to assess the flap neovascularization from the wound, by temporarily clamping the main pedicle. Only when flap perfusion has been assessed and found sufficient, the bridge is divided and skin closure achieved, also by using tissues from the vascular bridge flap to cover any residual areas. Manrique et al ${ }^{[122]}$ in 2018 described our experience with cross-leg flaps by performing a retrospective review of a case series of 53 patients treated between 1985 and 2017 in China Medical University Hospital, Taichung, Taiwan and Mayo Clinic, Rochester, MN, USA. The average follow-up time was 7.5 years. Complications rates were low (with two flap loss) and the overall limb salvage rate was $96.2 \%$. In our hands, cross-leg flaps, enhanced by the latest microsurgical developments, can still represent an option to avoid amputation in challenging lower extremity reconstructions, where no suitable vessels are found [Figure 3].

\section{CONCLUSION}

Up to date, many different options are available to reconstructive microsurgeons, therefore extremity reconstruction is reaching new levels of sophistication and the possibility of limb preservation is widening. It is important to remember, though, that this depends not only on the work of plastic surgeons, but also on their ability to interact with other practitioners and profit form new developments in other fields of study such as oncology, traumatology, radiology and medical engineering.

\section{DECLARATIONS}

\section{Authors' contributions}

Manuscript preparation and critical review: Bolletta A, Corrado R, Chen HC

Data collection: Bolletta A, Chen HC

Performance of surgery: Chen $\mathrm{HC}$ 


\section{Availability of data and materials}

The authors confirm that the data supporting the findings of this study are available within the article.

\section{Financial support and sponsorship}

None.

\section{Conflicts of interest}

The authors declared that there are no conflicts of interest.

\section{Ethical approval and consent to participate}

This study was performed with respect to the ethical standards of the Declaration of Helsinki, as revised in Tokyo 2004. Informed consent to participate was obtained from patients.

\section{Consent for publication}

Consent for publication was obtained from the patients.

\section{Copyright}

(c) The Author(s) 2019.

\section{REFERENCES}

1. Dibbs R, Grome L, Pederson WC. Free tissue transfer for upper extremity reconstruction. Semin Plast Surg 2019;33:17-23.

2. Engel H, Lin CH, Wei FC. Role of microsurgery in lower extremity reconstruction. Plast Reconstr Surg 2011;127 Suppl 1:228S-38.

3. Hollenbeck ST, Woo S, Komatsu I, Erdmann D, Zenn MR, et al. Longitudinal outcomes and application of the subunit principle to 165 foot and ankle free tissue transfers. Plast Reconstr Surg 2010;125:924-34.

4. Lee SH, Suh JT, Ahn TY, Hong SM, Lee HY. Differences between the upper extremity and the lower extremity in reconstruction using an anterolateral thigh perforator flap. Clin Orthop Surg 2017;9:348-54.

5. Abdelfattah U, Power HA, Song S, Min K, Suh HP, et al. Algorithm for free perforator flap selection in lower extremity reconstruction based on 563 cases. Plast Reconstr Surg August 2019; doi: 10.1097/PRS.0000000000006167.

6. Levin LS. The reconstructive ladder. An orthoplastic approach. Orthop Clin North Am 1993;24:393-409.

7. Gottlieb LJ, Krieger LM. From the reconstructive ladder to the reconstructive elevator. Plast Reconstr Surg 1994;93:1503-4.

8. Knobloch K, Vogt PM. The reconstructive clockwork of the twenty-first century: an extension of the concept of the reconstructive ladder and reconstructive elevator. Plast Reconstr Surg 2010;126:220e-2.

9. Schmidt K, Jakubietz MG, Gilbert F, Hausknecht F, Meffert RH, et al. Quality of life after flap reconstruction of the distal lower extremity: is there a difference between a pedicled suralis flap and a free anterior lateral thigh flap? Plast Reconstr Surg Glob Open 2019; 7:e2114.

10. King EA, Ozer K. Free skin flap coverage of the upper extremity. Hand Clin 2014;30:201-9.

11. Chim H, Ng ZY, Carlsen BT, Mohan AT, Saint-Cyr M. Soft tissue coverage of the upper extremity: an overview. Hand Clin 2014;30:459-73.

12. Chim H, Bakri K, Moran SL. Complications related to radial artery occlusion, radial artery harvest, and arterial lines. Hand Clin 2015;31:93-100.

13. Heller F, Wei W, Wei FC. Chronic arterial insufficiency of the hand with fingertip necrosis 1 year after harvesting a radial forearm free flap. Plast Reconstr Surg 2004;114:728-31.

14. Terzis JK, Kostopoulos VK. Free muscle transfer in posttraumatic plexopathies: part III. The hand. Plast Reconstr Surg 2009;124:1225-36.

15. Kay S, Pinder R, Wiper J, Hart A, Jones F, et al. Microvascular free functioning gracilis transfer with nerve transfer to establish elbow flexion. J Plast Reconstr Aesthetic Surg 2010;63:1142-9.

16. Pu LLQ. A comprehensive approach to lower extremity free-tissue transfer. Plast Reconstr Surg Glob Open 2017;5:e1228.

17. Cho EH, Shammas RL, Carney MJ, Weissler JM, Bauder AR, et al. Muscle versus fasciocutaneous free flaps in lower extremity traumatic reconstruction: a multicenter outcomes analysis. Plast Reconstr Surg 2018;141:191-9.

18. Bajantri B, Bharathi RR, Sabapathy SR. Wound coverage considerations for defects of the lower third of the leg. Indian J Plast Surg 2012;45:283-90.

19. Ricci JA, Crawford K, Ho OA, Lee BT, Patel KM, et al. Practical guidelines for venous thromboembolism prophylaxis in free tissue transfer. Plast Reconstr Surg 2016;138:1120-31.

20. Stranix JT, Lee ZH, Jacoby A, Anzai L, Avraham T, et al. Not all gustilo type IIIB fractures are created equal: arterial injury impacts limb salvage outcomes. Plast Reconstr Surg 2017;140:1033-41.

21. Ricci JA, Koolen PG, Shah J, Tobias AM, Lee BT, et al. Comparing the outcomes of different agents to treat vasospasm at 
microsurgical anastomosis during the Papaverine shortage. Plast Reconstr Surg 2016;138:401e-8.

22. Khouri RK, Shaw WW. Reconstruction of the lower extremity with microvascular free flaps: a 10-year experience with 304 consecutive cases. J Trauma 1989;29:1086-94.

23. Stranix JT, Lee ZH, Anzai L, Jacoby A, Avraham T, et al. Optimizing venous outflow in reconstruction of Gustilo IIIB lower extremity traumas with soft tissue free flap coverage: are two veins better than one? Microsurgery 2018;38:745-51.

24. Gustilo RB, Anderson JT. Prevention of infection in the treatment of one thousand and twenty-five open fractures of long bones: retrospective and prospective analyses. J Bone Joint Surg Am 1976;58:453-8.

25. Gustilo RB, Mendoza RM, Williams DN. Problems in the management of type III (severe) open fractures: a new classification of type III open fractures. J Trauma 1984;24:742-6.

26. Bulla A, Bolletta A, Fiorot L, Maffei M, Bandiera P, et al. Posterior tibial perforators relationship with superficial nerves and veins: A cadaver study. Microsurgery 2019;39:241-6.

27. Georgescu AV, Capota I, Matei I, Ardelean F, Avram A, et al. The place of local/regional perforator flaps in complex traumas of the forearm. J Hand Microsurg 2009;1:25-31.

28. Georgescu AV, Matei I, Ardelean F, Capota I. Microsurgical nonmicrovascular flaps in forearm and hand reconstruction. Microsurgery 2007;27:384-94.

29. Losco L, Lo Torto F, Maruccia M, Di Taranto G, Ribuffo D, et al. Modified single pedicle reverse adipofascial flap for fingertip reconstruction. Microsurgery 2019;39:221-7.

30. Innocenti M, Baldrighi C, Delcroix L, Adani R. Local perforator flaps in soft tissue reconstruction of the upper limb. Handchir Mikrochir Plast Chir 2009;41:315-21

31. Pignatti M, Ogawa R, Hallock GG, Mateev M, Georgescu AV, et al. The "Tokyo" consensus on propeller flaps. Plast Reconstr Surg 2011;127:716-22.

32. Georgescu AV, Matei IR. Propeller perforator flaps in forearm and hand reconstruction. Eur J Orthop Surg Traumatol 2019;29:357-66.

33. Lecours C, Saint-Cyr M, Wong C, Bernier C, Mailhot E, et al. Freestyle pedicle perforator flaps: clinical results and vascular anatomy. Plast Reconstr Surg 2010;126:1589-603.

34. Matei I, Georgescu A, Chiroiu B, Capota I, Ardelean F. Harvesting of forearm perforator flaps based on intraoperative vascular exploration: clinical experiences and literature review. Microsurgery 2008;28:321-30.

35. Lee BT, Lin SJ, Bar-Meir ED, Borud LJ, Upton J. Pedicled perforator flaps: a new principle in reconstructive surgery. Plast Reconstr Surg 2010;125:201-8.

36. Georgescu AV. Propeller perforator flaps in distal lower leg: evolution and clinical applications. Arch Plast Surg 2012;39:94-105.

37. van Waes OJF, Halm JA, Vermeulen J, Ashford BG. "The Practical Perforator Flap": the sural artery flap for lower extremity soft tissue reconstruction in wounds of war. Eur J Orthop Surg Traumatol Orthop Traumatol 2013;23 Suppl 2:S285-9.

38. Innocenti M, Menichini G, Baldrighi C, Delcroix L, Vignini L, et al. Are there risk factors for complications of perforator-based propeller flaps for lower-extremity reconstruction? Clin Orthop 2014;472:2276-86.

39. Gokrem S, Sarifakioğlu N, Toksoy K, Terzioğlu A, Aslan G. Effects of 360-degree pedicle torsion on island skin flaps: experimental study in rats. J Reconstr Microsurg 2005;21:313-6.

40. Selvaggi G, Anicic S, Formaggia L. Mathematical explanation of the buckling of the vessels after twisting of the microanastomosis. Microsurgery 2006;26:524-8.

41. Topalan M, Bilgin SS, Ip WY, Chow SP. Effect of torsion on microarterial anastomosis patency. Microsurgery 2003;23:56-9.

42. Koshima I, Moriguchi T, Etoh H, Tsuda K, Tanaka H. The radial artery perforator-based adipofascial flap for dorsal hand coverage. Ann Plast Surg 1995;35:474-9.

43. Hubmer MG, Fasching T, Haas F, Koch H, Schwarzl F, et al. The posterior interosseous artery in the distal part of the forearm. Is the term "recurrent branch of the anterior interosseous artery" justified? Br J Plast Surg 2004;57:638-44.

44. Bekara F, Herlin C, Somda S, de Runz A, Grolleau JL, et al. Free versus perforator-pedicled propeller flaps in lower extremity reconstruction: What is the safest coverage? A meta-analysis. Microsurgery 2018;38:109-19.

45. Dong KX, Xu YQ, Fan XY, Xu LJ, Su XX, et al. Perforator pedicled propeller flaps for soft tissue coverage of lower leg and foot defects. Orthop Surg 2014;6:42-6.

46. Gir P, Cheng A, Oni G, Mojallal A, Saint-Cyr M. Pedicled-perforator (propeller) flaps in lower extremity defects: a systematic review. J Reconstr Microsurg 2012;28:595-601.

47. Nelson JA, Fischer JP, Brazio PS, Kovach SJ, Rosson GD, et al. A review of propeller flaps for distal lower extremity soft tissue reconstruction: Is flap loss too high? Microsurgery 2013;33:578-86.

48. Herter F, Ninkovic M, Ninkovic M. Rational flap selection and timing for coverage of complex upper extremity trauma. J Plast Reconstr Aesthetic Surg 2007;60:760-8.

49. Heller L, Levin LS. Lower extremity microsurgical reconstruction. Plast Reconstr Surg 2001;108:1029-41; quiz 1042.

50. Philandrianos C, Moullot P, Gay AM, Bertrand B, Legré R, et al. Soft tissue coverage in distal lower extremity open fractures: comparison of free anterolateral thigh and free latissimus dorsi flaps. J Reconstr Microsurg 2018;34:121-9.

51. Wang HD, Alonso-Escalante JC, Cho BH, DeJesus RA. Versatility of free cutaneous flaps for upper extremity soft tissue reconstruction. J Hand Microsurg 2017;9:58-66.

52. Ninkovic M, Mooney EK, Ninkovic M, Kleistil T, Anderl H. A new classification for the standardization of nomenclature in free flap wound closure. Plast Reconstr Surg 1999;103:903-14; discussion 915-7.

53. Chan JK, Harry L, Williams G, Nanchahal J. Soft-tissue reconstruction of open fractures of the lower limb: muscle versus 
fasciocutaneous flaps. Plast Reconstr Surg 2012;130:284e-95.

54. Gosain A, Chang N, Mathes S, Hunt TK, Vasconez L. A study of the relationship between blood flow and bacterial inoculation in musculocutaneous and fasciocutaneous flaps. Plast Reconstr Surg 1990;86:1152-62; discussion 1163.

55. Pederson WC. Upper extremity microsurgery. Plast Reconstr Surg 2001;107:1524-37; discussion 1538-9, 1540-3.

56. Yazar S, Lin CH, Lin YT, Ulusal AE, Wei FC. Outcome comparison between free muscle and free fasciocutaneous flaps for reconstruction of distal third and ankle traumatic open tibial fractures. Plast Reconstr Surg 2006;117:2468-75; discussion 2476-7.

57. Rodriguez ED, Bluebond-Langner R, Copeland C, Grim TN, Singh NK, et al. Functional outcomes of posttraumatic lower limb salvage: a pilot study of anterolateral thigh perforator flaps versus muscle flaps. J Trauma 2009;66:1311-4.

58. Paro J, Chiou G, Sen SK. Comparing muscle and fasciocutaneous free flaps in lower extremity reconstruction--does it matter? Ann Plast Surg 2016;76 Suppl 3:S213-5.

59. Gordon L, Buncke HJ, Alpert BS. Free latissimus dorsi muscle flap with split-thickness skin graft cover: a report of 16 cases. Plast Reconstr Surg 1982;70:173-8.

60. Schaverien MV, Hart AM. Free muscle flaps for reconstruction of upper limb defects. Hand Clin 2014;30:165-83, v-vi.

61. Whitney TM, Buncke HJ, Alpert BS, Buncke GM, Lineaweaver WC. The serratus anterior free-muscle flap: experience with 100 consecutive cases. Plast Reconstr Surg 1990;86:481-90; discussion 491.

62. Logan SE, Alpert BS, Buncke HJ. Free serratus anterior muscle transplantation for hand reconstruction. Br J Plast Surg 1988;41:639-43.

63. Dumont CE, Domenghini C, Kessler J. Donor site morbidity after serratus anterior free muscular flap: a prospective clinical study. Ann Plast Surg 2004;52:195-8.

64. Taylor GI, Corlett RJ, Boyd JB. The versatile deep inferior epigastric (inferior rectus abdominis) flap. Br J Plast Surg 1984;37:330-50.

65. Rao VK, Baertsch A. Microvascular reconstruction of the upper extremity with the rectus abdominis muscle. Microsurgery 1994;15:746-50.

66. Horch RE, Stark GB. The rectus abdominis free flap as an emergency procedure in extensive upper extremity soft-tissue defects. Plast Reconstr Surg 1999;103:1421-7.

67. Hallock GG. A paradigm shift in flap selection protocols for zones of the lower extremity using perforator flaps. J Reconstr Microsurg 2013;29:233-40.

68. Koshima I, Yamamoto T, Narushima M, Mihara M, Iida T. Perforator flaps and supermicrosurgery. Clin Plast Surg 2010;37:683-9, vii-iii.

69. Saint-Cyr M, Wong C, Buchel EW, Colohan S, Pederson WC. Free tissue transfers and replantation. Plast Reconstr Surg 2012;130:858e-78.

70. Taylor GI. The angiosomes of the body and their supply to perforator flaps. Clin Plast Surg 2003;30:331-42, v.

71. Demirtas Y, Kelahmetoglu O, Cifci M, Tayfur V, Demir A, et al. Comparison of free anterolateral thigh flaps and free musclemusculocutaneous flaps in soft tissue reconstruction of lower extremity. Microsurgery 2010;30:24-31.

72. Park JE, Rodriguez ED, Bluebond-Langer R, Bochicchio G, Christy MR, et al. The anterolateral thigh flap is highly effective for reconstruction of complex lower extremity trauma. J Trauma 2007;62:162-5.

73. Hong JP. The use of supermicrosurgery in lower extremity reconstruction: the next step in evolution. Plast Reconstr Surg 2009;123:230-5.

74. Nazerali RS, Pu LLQ. Free tissue transfer to the lower extremity: a paradigm shift in flap selection for soft tissue reconstruction. Ann Plast Surg 2013;70:419-22.

75. Hong JPJ, Goh TLH, Choi DH, Kim JJ, Suh HS. The efficacy of perforator flaps in the treatment of chronic osteomyelitis. Plast Reconstr Surg 2017;140:179-88.

76. Pederson WC, Grome L. Microsurgical reconstruction of the lower extremity. Semin Plast Surg 2019;33:54-8.

77. Hong JP, Koshima I. Using perforators as recipient vessels (supermicrosurgery) for free flap reconstruction of the knee region. Ann Plast Surg 2010;64:291-3.

78. Hong JP, Yim JH, Malzone G, Lee KJ, Dashti T, et al. The thin gluteal artery perforator free flap to resurface the posterior aspect of the leg and foot. Plast Reconstr Surg 2014;133:1184-91.

79. Momeni A, Krischak S, Bannasch $\mathrm{H}$. The thoracodorsal artery perforator flap with a vascularized scapular segment for reconstruction of a composite lower extremity defect. Microsurgery 2006;26:515-8.

80. Kim KN, Hong JP, Park CR, Yoon CS. Modification of the elevation plane and defatting technique to create a thin thoracodorsal artery perforator flap. J Reconstr Microsurg 2016;32:142-6.

81. Yoon CS, Noh HJ, Malzone G, Suh HS, Choi DH, et al. Posterior interosseous artery perforator-free flap: treating intermediate-size hand and foot defects. J Plast Reconstr Aesthetic Surg 2014;67:808-14.

82. Jeng SF, Wei FC. Classification and reconstructive options in foot plantar skin avulsion injuries. Plast Reconstr Surg 1997;99:1695703; discussion 1704-5.

83. Shanahan RE, Gingrass RP. Medial plantar sensory flap for coverage of heel defects. Plast Reconstr Surg 1979;64:295-8.

84. Koshima I, Urushibara K, Inagawa K, Hamasaki T, Moriguchi T. Free medial plantar perforator flaps for the resurfacing of finger and foot defects. Plast Reconstr Surg 2001;107:1753-8.

85. Zelken JA, Lin CH. An algorithm for forefoot reconstruction with the innervated free medial plantar flap. Ann Plast Surg 2016;76:221-6.

86. Löfstrand JG, Lin CH. Reconstruction of defects in the weight-bearing plantar area using the innervated free medial plantar (Instep) flap. Ann Plast Surg 2018;80:245-51.

87. Sinha AK, Wood MB, Irons GB. Free tissue transfer for reconstruction of the weight-bearing portion of the foot. Clin Orthop 1989;(242):269-71. 
88. Sönmez A, Bayramiçli M, Sönmez B, Numanoğlu A. Reconstruction of the weight-bearing surface of the foot with nonneurosensory free flaps. Plast Reconstr Surg 2003;111:2230-6.

89. Chang KN, DeArmond SJ, Buncke HJ. Sensory reinnervation in microsurgical reconstruction of the heel. Plast Reconstr Surg 1986;78:652-64.

90. Fox CM, Beem HM, Wiper J, Rozen WM, Wagels M, et al. Muscle versus fasciocutaneous free flaps in heel reconstruction: systematic review and meta-analysis. J Reconstr Microsurg 2015;31:59-66.

91. Kremer T, Bickert B, Germann G, Heitmann C, Sauerbier M. Outcome assessment after reconstruction of complex defects of the forearm and hand with osteocutaneous free flaps. Plast Reconstr Surg 2006;118:443-54; discussion 455-6.

92. Soucacos PN, Korompilias AV, Vekris MD, Zoubos A, Beris AE. The free vascularized fibular graft for bridging large skeletal defects of the upper extremity. Microsurgery 2011;31:190-7.

93. Houdek MT, Wagner ER, Wyles CC, Nanos GP, Moran SL. New options for vascularized bone reconstruction in the upper extremity. Semin Plast Surg 2015;29:20-9.

94. Bodde EWH, de Visser E, Duysens JEJ, Hartman EHM. Donor-site morbidity after free vascularized autogenous fibular transfer: subjective and quantitative analyses. Plast Reconstr Surg 2003;111:2237-42.

95. Momoh AO, Yu P, Skoracki RJ, Liu S, Feng L, et al. A prospective cohort study of fibula free flap donor-site morbidity in 157 consecutive patients. Plast Reconstr Surg 2011;128:714-20.

96. Rendenbach C, Rashad A, Hansen L, Kohlmeier C, Dyck ML, et al. Functional donor site morbidity longer than one year after fibula free flap: a prospective biomechanical analysis. Microsurgery 2018;38:395-401.

97. Jones DB, Rhee PC, Bishop AT, Bishop AT, Shin AY. Free vascularized medial femoral condyle autograft for challenging upper extremity nonunions. Hand Clin 2012;28:493-501.

98. Kakar S, Duymaz A, Steinmann S, Shin AY, Moran SL. Vascularized medial femoral condyle corticoperiosteal flaps for the treatment of recalcitrant humeral nonunions. Microsurgery 2011;31:85-92.

99. Rao SS, Sexton CC, Higgins JP. Medial femoral condyle flap donor-site morbidity: a radiographic assessment. Plast Reconstr Surg 2013;131:357e-62.

100. Aktuglu K, Erol K, Vahabi A. Ilizarov bone transport and treatment of critical-sized tibial bone defects: a narrative review. J Orthop Traumatol 2019;20:22.

101. Henry SL, Frome BA, Pederson WC. Vascularized bone transfer for severe injury around the ankle. Microsurgery 2009;29:353-60.

102. Pederson WC, Person DW. Long bone reconstruction with vascularized bone grafts. Orthop Clin North Am 2007;38:23-35.

103. Pannunzio ME, Chhabra AB, Golish SR, Brown MR, Pederson WC. Free fibula transfer in the treatment of difficult distal tibia fractures. J Reconstr Microsurg 2007;23:11-8.

104. Innocenti M, Lucattelli E, Daolio PA, Bastoni S, Marini E, et al. Calcaneal reconstruction after total calcanectomy with iliac crest free flap. Microsurgery 2019; doi:10.1002/micr.30452.

105. Li J, Wang Z, Guo Z, Yang M, Chen G, et al. Composite biological reconstruction following total calcanectomy of primary calcaneal tumors. J Surg Oncol 2012;105:673-8.

106. Oh C, Carlsen BT. New innovations in targeted muscle reinnervation: a critical analysis review. JBJS Rev 2019;7:e3.

107. Flint LM, Richardson JD. Arterial injuries with lower extremity fracture. Surgery 1983;93:5-8.

108. Hansen ST. The type-IIIC tibial fracture. Salvage or amputation. J Bone Joint Surg Am 1987;69:799-800.

109. Goodman RS. The type-IIIC tibial fracture. Salvage or amputation. J Bone Joint Surg Am 1988;70:311.

110. Hertel R, Strebel N, Ganz R. Amputation versus reconstruction in traumatic defects of the leg: outcome and costs. J Orthop Trauma 1996;10:223-9.

111. MacKenzie EJ, Jones AS, Bosse MJ, Castillo RC, Pollak AN, et al. Health-care costs associated with amputation or reconstruction of a limb-threatening injury. J Bone Joint Surg Am 2007;89:1685-92.

112. Ricci JA, Abdou SA, Stranix JT, Lee ZH, Anzai L, et al. Reconstruction of Gustilo IIIC Injuries of the Lower Extremity. Plast Reconstr Surg. 2019; doi: 10.1097/PRS.0000000000006063.

113. Toia F, Zabbia G, Roggio T, Pirrello R, D’Arpa S, et al. Vascular grafts and flow-through flaps for microsurgical lower extremity reconstruction. J Reconstr Microsurg 2017;33:S14-9.

114. Zheng X, Zhan Y, Li H, Zhang Z, Xue X, et al. Emergency repair of severe limb injuries with free flow-through chimeric anterolateral thigh perforator flap. Ann Plast Surg 2019; doi: 10.1097/SAP.0000000000001913.

115. Fujiki M, Miyamoto S, Sakuraba M. Flow-through anastomosis for both the artery and vein in leg free flap transfer. Microsurgery 2015;35:536-40.

116. Ducic I, Rao SS, Attinger CE. Outcomes of microvascular reconstruction of single-vessel lower extremities: limb salvage versus amputation. J Reconstr Microsurg. 2009;25:475-8.

117. Stark RB. Pre-operatively applied, mated, plaster of paris casts as an aid in the migration of open-pedicle cross leg flaps. Plast Reconstr Surg (1946) 1947;2:433-8.

118. Stark RB. The cross-leg flap procedure. Plast Reconstr Surg (1946) 1952;9:173-204.

119. Morris AM, Buchan AC. The place of the cross-leg flap in reconstructive surgery of the lower leg and foot: a review of 165 cases. Br J Plast Surg 1978;31:138-42.

120. Yu ZJ, Zeng BF, Huang YC, He HG, Sui SP, et al. Application of the cross-bridge microvascular anastomosis when no recipient vessels are available for anastomosis: 85 cases. Plast Reconstr Surg 2004;114:1099-107.

121. Yu L, Tan J, Cai L, Yu G, Tao S, et al. Repair of severe composite tissue defects in the lower leg using two different cross-leg free 
composite tissue flaps. Ann Plast Surg 2012;68:83-7.

122. Manrique OJ, Bishop SN, Ciudad P, Adabi K, Martinez-Jorge J, et al. Lower extremity limb salvage with cross leg pedicle flap, cross leg free flap, and cross leg vascular cable bridge flap. J Reconstr Microsurg 2018;34:522-9. 